\title{
Resistance of human leukocytes to vesicular stomatitis virus infection as one of the innate antiviral immune activities; participation of cell subpopulations
}

\author{
Ewa Zaczynska, Danuta Duś, Maria Paprocka and Zofia Błach-Olszewska \\ Institute of Immunology and Experimental Therapy, Polish Academy of Sciences, Wroclaw, Poland
}

\begin{abstract}
Among reactions of innate immunity, resistance of human peripheral blood leukocytes (PBL) to viral infection seems important. The purpose of our study was to find, which of the subpopulations of PBL is the most responsible for the innate antiviral immunity of these cells. The innate immunity was measured by using the direct method of infection of leukocytes with vesicular stomatitis virus (VSV). The lack of VSV replication by infected leukocytes $\left(0-1 \log \mathrm{TCID}_{50}\right)$ was taken as an indicator for complete immunity; a low level of VSV (2-3 log) for partial immunity; and high VSV titer (more than $4 \mathrm{log}$ ) for no immunity. The resistance/innate immunity of whole PBL and subpopulations such as: adherent cells, fractions enriched in lymphocytes T, and lymphocytes B (separated on column with nylon wool), NK(+) and NK(-) (separated by microbeads activated cell sorting MACS) differ from each other. All fractions express higher resistance/innate immunity than the whole PBL. NK(+) cells were found the most resistant fraction of PBL to VSV infection. The results indicate that among the leukocytes in PBL the regulation mechanisms of innate immunity exist. The study on the mechanism of innate immunity regulation as well as the role of NK in innate immunity of PBL must be continued
\end{abstract}

Key words: Human leukocytes - Innate immunity - VSV resitance - NK cells

\section{Introduction}

Innate immunity is one of the branches of a host's defense which protects the organism from pathogen infection. The innate immunity differs from acquired immunity with respect to receptors and pathogen structures recognized by them, cells engaged and kind of developed mechanisms [1]. The mechanisms of innate immunity include:

- phagocytosis,

- production of cytokines, interleukins, chemokines, adhesion molecules,

- MHC-independent killing by NK cells and complement (activated alternatively or by lectin) $[2,3]$

- resistance of leukocytes and other cells to viral infections ex vivo.

The resistance of murine macrophages and Kupffer cells to HSV infection has been known much earlier [4-7]. We found that the resistance is present not only

Correspondence: E. Zaczyńska, Institute of Immunology and Experimental Therapy, Polish Academy of Sciences, R. Weigla Str. 12, 53-114 Wroclaw, Poland; tel.: (+4871) 3371172 , fax.: (+4871) 3371382, e-mail: ezacz@immuno.iitd.pan.wroc.pl in macrophages, but also in other cells ex vivo, and that is not directed against HSV only, but also against viruses belonging to different taxonomic groups such as encephalomyocarditis virus (EMCV, Picornaviridae), and vesicular stomatitis virus (VSV, Rhabdoviridae) [8-11]. The resistance of freshly isolated human peripheral blood leukocytes to viral infection was a good reason for elaboration the test for measuring the degree of innate immunity [8]. Among different viral candidates, VSV was selected as the indicatory virus for the detection of innate antiviral immunity. This virus does not cause natural infection in human population in Europe including Poland. We did not find VSV and EMCV-neutralizing activity in 12 human sera and presence of anti-HSV-1 antibodies with titer ranged 8-512 neutralizing units $/ \mathrm{ml}$. An additional advantage of this virus is its broad tropism. VSV is able to replicate in different human and animal cells. Although this virus is wide used in gene transfer and gene therapy, the cell receptor for VSV has been not known yet. In the structure of the receptor should be a membrane lipid molecule in common with almost all cells. The phosphatidylserine was considered as responsible for VSV receptor function, but it was not confirmed by Coil and Miller [12]. Our results showed 
that kinetics of VSV replication in freshly isolated human peripheral blood leukocytes (PBL) indicates degree of the resistance to viral infection. The lack of VSV replication in the cells ( $0-1 \log$ TCID50) indicates complete resistance, low level of VSV replication (2-3 $\log$ ) partial resistance, and high VSV titer (more than 4 $\log$ ) very low or lack of the resistance [9].

The strongest resistance is observed immediately after isolation of the cells from the blood. During 1 to 4 days in vitro culture of leukocytes (before VSV infection), the resistance is progressively reduced. The results of our study, performed on more than 300 individuals, indicate that the resistance is individually differentiated. Blood donors could be divided for a group with good, partial, and lack of resistance. The non specific character of the resistance of PBL present in cells ex vivo, dependence on constitutive IFN-s and TNF $\alpha$, individual differentiation, decided that the resistance was considered by us as innate antiviral immunity. The highest level of immunity was observed in person in age 30-40, much lower in individuals $>60$ [13]. Individuals with frequent infections of upper respiratory tract, as well as with cancer diseases express statistically lower innate immunity to compare with healthy persons $[8,14]$. The cells responsible for an innate immunity are considered NK cells, dendritic cells (DC), macrophages, $\gamma \delta \mathrm{T}$ lymphocytes, neutrophils. They produce different cytokines and other agents or take part in killing of infected cells. The aim of our study was to find a cell population in human PBL, which is resistant to VSV and is responsible for the immunity.

\section{Materials and methods}

Blood donors. Blood taken from a peripheral vein healthy volunteers were obtained from Regional Transfusion Center. The persons were $18-45$ years old.

Peripheral blood leukocytes (PBL). Leukocytes were isolated from heparinized peripheral blood $(10 \mathrm{U} / \mathrm{ml})$ by gradient centrifugation in Gradisol G with a density of $1.115 \mathrm{~g} / \mathrm{ml}$ (Aqua Medica, Poznan, Poland). Five $\mathrm{ml}$ of blood were layered on three $\mathrm{ml}$ of Gradisol and centrifuged for $30 \mathrm{~min}$. at $400 \times \mathrm{g}$. The leukocytes were collected from the interphase, washed two times with Dulbecco medium supplemented with $2 \%$ of calf serum (c. s.) and suspended in this medium at a density of $2 \times 10^{6}$ cells $/ \mathrm{ml}$.

T- and B-cell preparation. To remove adherent cells (mainly macrophages), suspension of leukocytes was put on a glass plate and incubated for $1 \mathrm{~h}$ at $37^{\circ} \mathrm{C}$ and $5 \% \mathrm{CO}_{2}$. Lymphocytes, free from macrophages, were passed through a nylon wool to separate $\mathrm{T}$ and $\mathrm{B}$ lymphocytes according to Julius et al. [2].

NK cells isolation by MACS (magnetic cell sorting). NK-cells were isolated from human leukocytes by magnetic microBeads active cell sorting (MACS). Using the NK Cell Isolation Kit II, human NK cells were isolated by depletion of non-NK cell (negative selection). Non-NK cells were indirectly magnetically labeled with a cocktail of biotin-conjugated monoclonal antibodies, as primary labeling reagent, and anti-biotin monoclonal antibodies con- jugated to MicroBeads, as secondary labeling reagent. The magnetically labeled non-NK cells were depleted by retaining them on a MACS column in the magnetic field of a MACS separator, unlabeled NK cells pass through the column. The NK cells were examined by flow cytometry. Stain aliquots of the cells fractions with antibody against a NK cell marker- CD56-PE and optional, against a $\mathrm{T}$ cell marker- CD3-FITC.

Vesicular stomatitis virus (VSV), Indiana strain, Rhabdoviridae, was multiplied and titrated in L929 cells (ATCC CCL1). The titer of virus was expressed in reference to the value of TCID50 (tissue culture infectious dose), based on the cytopathic effect induced by this virus in $50 \%$ of the cells in the tissue culture.

Replication of VSV in PBL, NK, T-, B- cells and macrophages. Freshly isolated cells $\left(2 \times 10^{6} / \mathrm{ml}\right)$ were infected with VSV at concentration of $100 \mathrm{TCID}_{50} / \mathrm{ml}$. Following $40 \mathrm{~min}$. adsorption at room temperature, the virus was washed out three times with $5 \mathrm{ml}$ RPMI, with $2 \%$ c.s.. A sample of infected cells was kept at a temperature of $4^{\circ} \mathrm{C}$, to serve as a control of the starting level of the virus. The cells were incubated at $37^{\circ} \mathrm{C}$, and samples of medium above the infected cells were collected each day and virus was tittered in L929 cells. The titer of virus was expressed in units of $\mathrm{TCID}_{50}$.

Assessment of innate immunity. The assessment of resistance/innate immunity was evaluated on the basis of the highest titer of VSV in infected leukocytes expressed in the log scale. The titer of VSV equal to $0-1 \log$ TCID $_{50}$ was taken as complete innate immunity, a value of 2-3 $\log \mathrm{TCID}_{50}$ as partial innate immunity and a value of $\geq 4$ or more $\log \operatorname{TCID}_{50}$ indicates deficiency of the immunity.

Statistical analysis. Results were analysed by using Student's test for independent variables, and significant values are considered when $\mathrm{p}<0.05$

\section{Results}

\section{Effect of cell separation procedure on innate immunity of leukocytes}

To explain how procedure of separation influence the resistance/innate immunity of leukocytes, whole PBL and separated cell fractions were investigated. At first, adherent cells were separated. Non-adhered cells suspension was passed through a nylon wool packed column to obtain the fractions enriched in T and in B lymphocytes. Each of the cell fractions (all at concentration $2 \times 10^{6}$ cells $/ \mathrm{ml}$ ) was divided into two parts. Half of them were infected with VSV at once (time $t=0$ ), the second part was infected after 1 day of incubation $(\mathrm{t}=24)$ at $37^{\circ} \mathrm{C}$. Kinetics of VSV replication in both fractions was compared. Results of 5 independent experiments are presented in Fig. 1. In PBL VSV reached level 1-2 $\log \mathrm{TCID}_{50}$, however, in the cells preincubated one day before infection VSV, the virus reached the titer even $7 \log$. This high titer of VSV means that the innate immunity, previously present in leukocytes, was much reduced during culture in vitro. We were, however, surprised with the results obtained on the separated fractions. All fractions (adherent, enriched in $\mathrm{T}$ and $\mathrm{B}$ lymphocytes) expressed stronger 

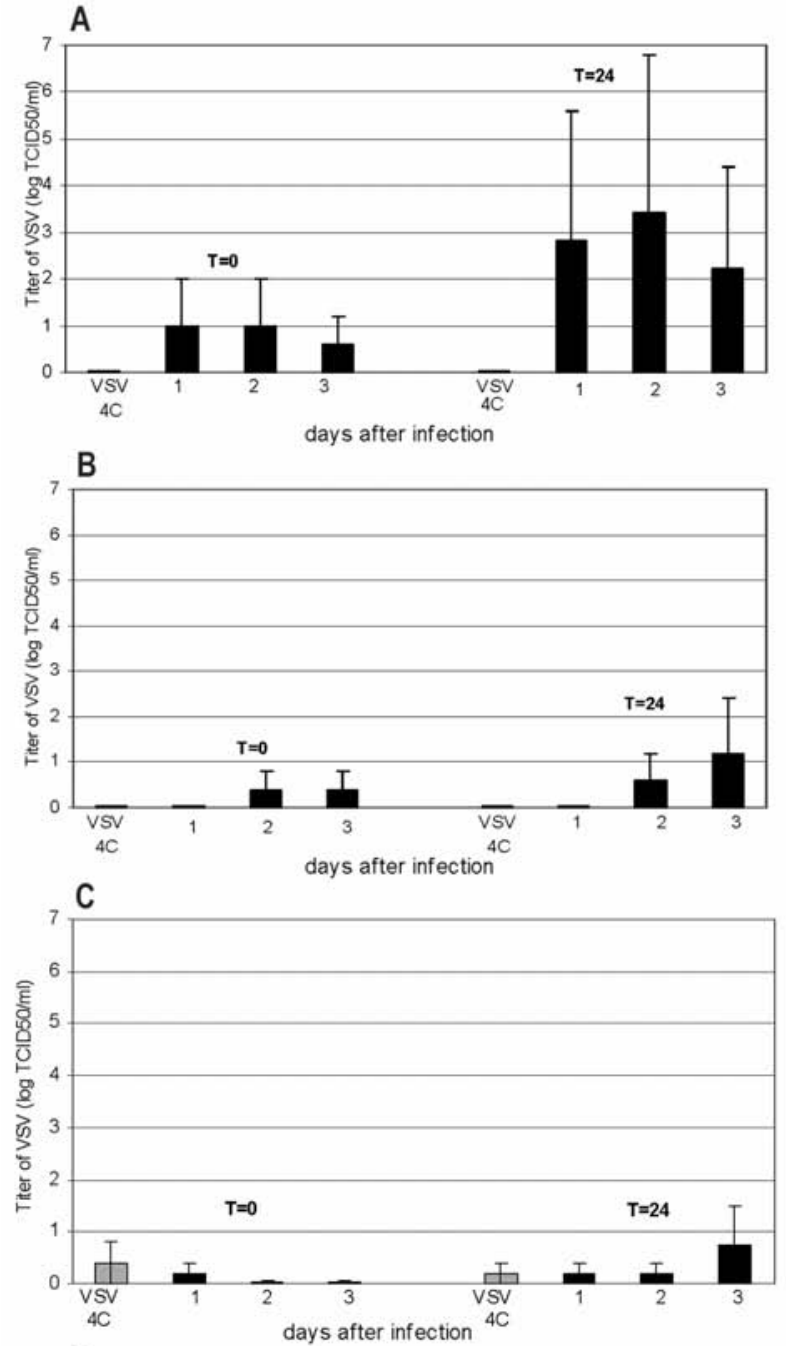

D

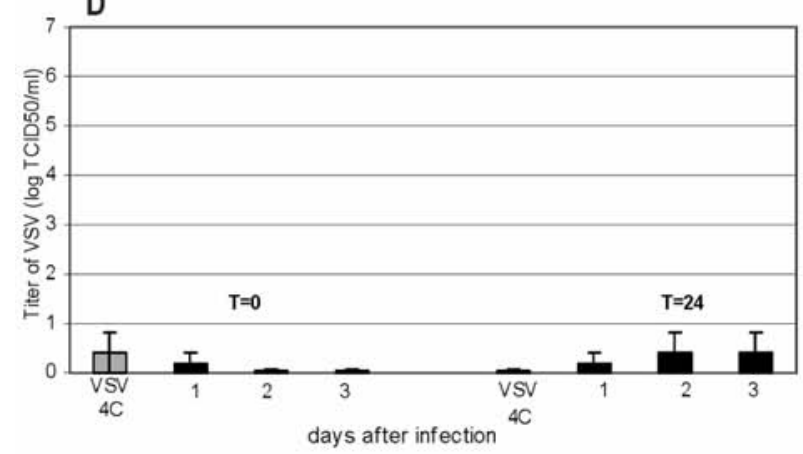

Fig. 1. Kinetics of VSV replication in whole PBL (A), adherent cells $(\mathbf{B})$, fractions enriched in lymphocytes $\mathrm{T}(\mathbf{C})$, and lymphocytes B (D) $(n=5)$. The PBL and cell fractions at concentrations $2 \times 106$ cells $/ \mathrm{ml}$ were infected with VSV immediately after cells isolation $(t=0)$, or after one day culture in vitro $(t=24)$. Kinetics of virus replication was studied. To each experiment, a sample of VSV infected cells, placed at $4^{\circ} \mathrm{C}$ was added. The VSV in samples from infected cells were titrated in $\mathrm{L}_{929}$ cells.

than whole PBL resistance to VSV infection. When the cells were preincubated one day before infection, the sensitivity to VSV infection was not increased. Only in

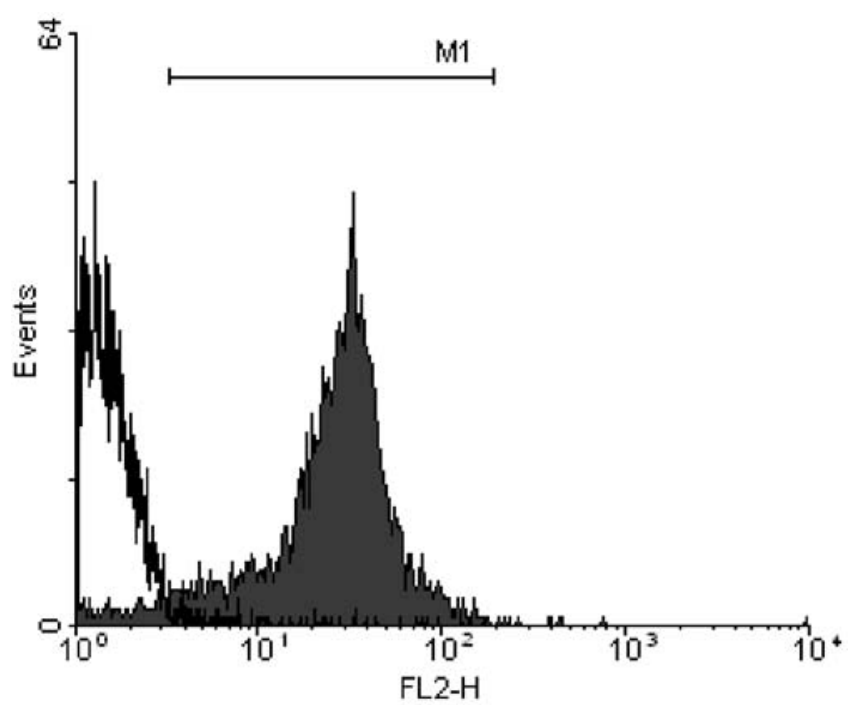

Fig. 2. Cytofluorometric profile of NK cells isolated from PBL by MACS method.

the adherent cells incubated 1 day, VSV reached the titer 1-2 log. The results show that separated cell fractions have quite different (stronger) resistance/innate immunity than the whole PBL ex vivo.

\section{Role of NK cells in resistance/innate immunity of $P B L$}

The importance of NK cells for the resistance/ innate immunity of PBL was studied. NK cells separation from whole PBL was performed. Use the MACS method $95 \%$ purity of NK cells was achieved (Fig. 2). The experiments on innate immunity of $\mathrm{NK}(+)$, NK(-) and whole PBL were performed similarly as previously. Part of PBL, NK(+), and NK(-) cell suspension was infected with VSV immediately after isolation, and the second part was infected after one day of incubation. Kinetics of VSV replication for both parts of cells was compared. Results are presented on Fig. 3. Results obtained confirm previous observation that the separation of cell fractions caused changing the intensity of innate immunity. Separated cell populations expressed stronger innate immunity. The most resistant to VSV infection were found $\mathrm{NK}(+)$ cells. Further five comparative experiments on the resistance $\mathrm{NK}(+)$ and NK(-) cells to VSV infection confirmed the observation (Fig. 4). To explain the reason of $\mathrm{NK}(+)$ high resistance we try to reduce it by several days culture of the cells in vitro before VSV infection. The suspension of separated NK cells was divided into 4 portions. One was infected with the virus immediately after cell isolation, the others after one, two or three days incubation in vitro. As is shown in Fig. 5, the resistance to VSV infection was not reduced, so further study concerned the nature of the NK resistance have to be continued. 


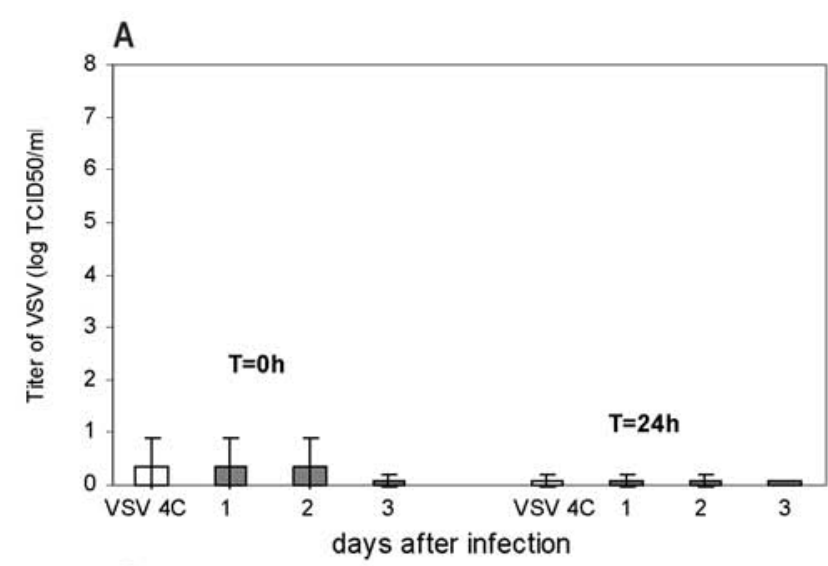

B
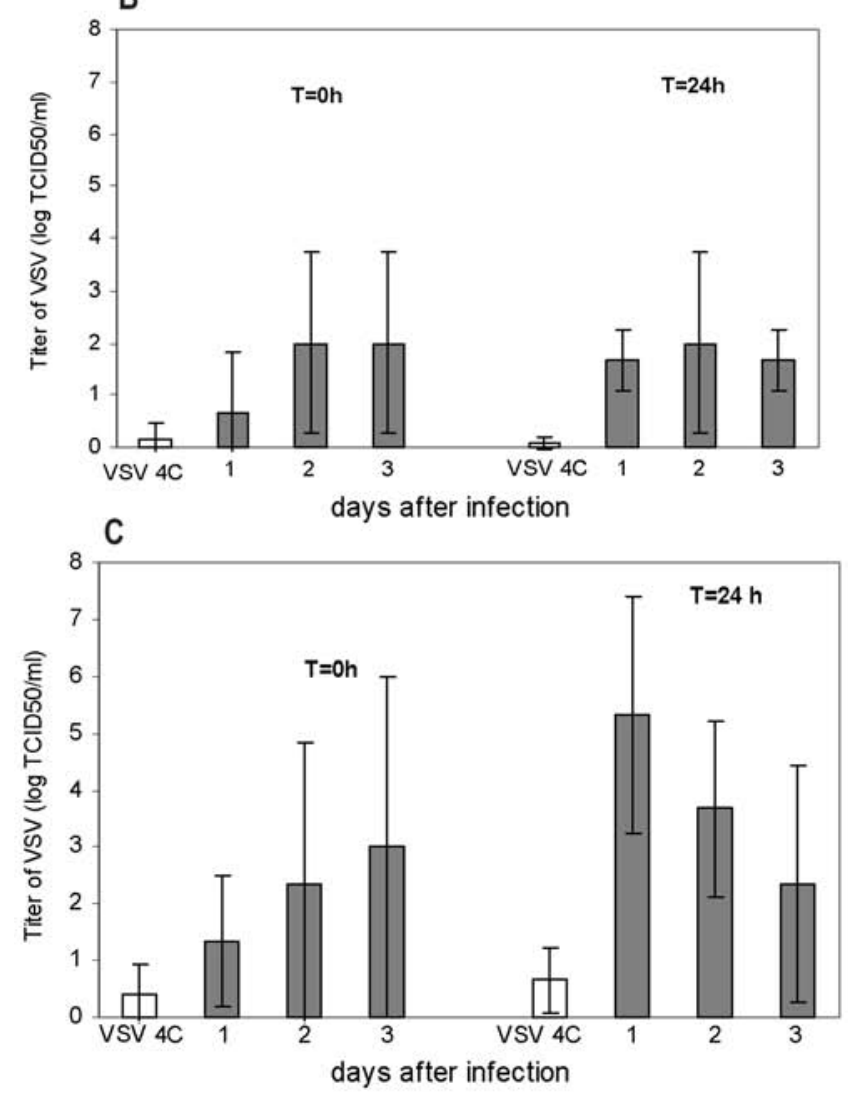

Fig. 3. Kinetics of VSV replication in whole PBL (A), in fraction $\mathrm{NK}(+)(\mathbf{B})$ and fraction $\mathrm{NK}(-)$ cells $(\mathbf{C})(\mathrm{n}=3)$.

\section{Discussion}

Results of innate immunity studies in the whole human PBL-s are frequently questionable. Criticism usually concerns the question: why the study was not done on separated, well defined cell fraction. Results of our study on the separated cell fractions: adherent, lymphocytes enriched in $\mathrm{T}$ and $\mathrm{B}$ cells showed that they expressed higher resistance/innate immunity than the whole PBL. The same tendency was observed when separated cell population $\mathrm{NK}(+)$ and NK(-) were isolated from PBL. The mechanism

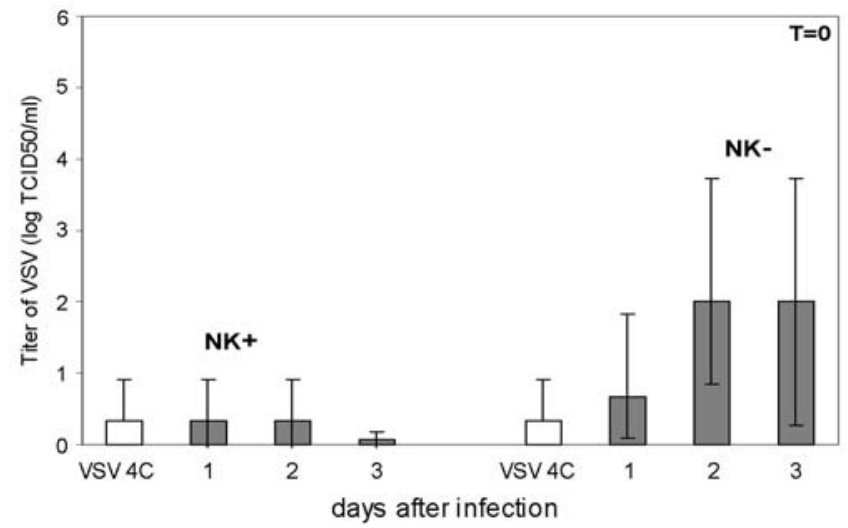

Fig. 4. Comparison the sensitivity of $\mathrm{NK}(+)$ and $\mathrm{NK}(-)$ to VSV infection. $(n=5)$. The cells were infected only in $\mathrm{t}=0$.

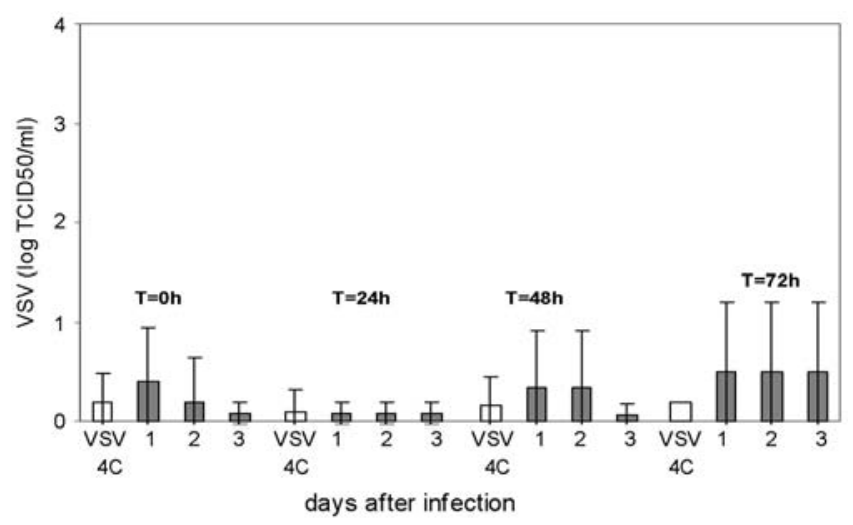

Fig. 5. Effect of NK cell culture in vitro before infection with VSV on their resistance to the virus. The cells were infected with VSV immediately after isolation $(\mathrm{t}=0)$ or after one $(\mathrm{t}=24)$, two $(\mathrm{t}=48)$ or three $(\mathrm{t}=72)$ days culture in vitro.

responsible for the difference in resistance between whole PBL and their subpopulations is unknown. Probably depends on cell contact or constitutive production of inhibitory mediators for innate immunity by PBL. Inhibitory effect caused by cell contact was described by Zitvogel [15] for NK and DC cells. The regulation of innate and acquired immunity in this study, depended on kinetics of NK activation. Strongly activated NK produced more IFN $\gamma$ and proliferated. Then they kill immature DC. When kinetics of NK activation is weaker the maturation process of DC starts and development of acquired immunity is stimulated. In that way the innate as well as acquired immunity is regulated. In the regulation of innate immunity measured by resistance to viral infections may take part for example constitutive cytokines (IL10 , TGF $\beta$ ), or SOCS (suppressor of cytokine signaling), Tyro-3 receptors, adenosine released by cells or other unknown molecules [16].

The other problem is how important are NK cells for PBL resistance/innate immunity to viral infection. These cells are very important element of reactions of 
innate immunity. NK are responsible for MHC-independent killing of pathogen infected cells. They are also able to produce antiviral cytokine IFN $\gamma[17,18]$. In our study we found NK cells as the most resistant to VSV infection. The resistance may result from the presence of very high innate immunity, which is not reduced during three days NK culture before VSV infection. The other reason of this resistance may be a lack of receptors for VSV on the membrane of NK cells. The problem of VSV resistance is not easy to solve, because the special receptor structure for the virus is not known. Rosenthal et al. [19] found that VSV is able to replicate in NK cells without cytopathic effect. According to them the cloned lines of natural killer cells were readily and persistently infected by VSV. VSV-infected NK cells continued to proliferate, express viral surface antigen and produce infectious virus. In view of these results NK cells used by authors are sensitive to VSV infection. The importance of NK cells in the resistance/innate immunity remains to be established.

\section{References}

[1] Błach-Olszewska Z. Innate immunity: cells, receptors, and signaling pathways. Arch Immunol Ther Exp. 2005; 53:245253.

[2] Julius MH, Simpson E, Herzenberg LA. A rapid method for the isolation of functional thymus-derived murine lymphocytes. Eur J Immunol. 1973;3:645-649.

[3] Selander B, Martesson U, Weintraub A, Holmstrum E, Matsushita M, Thiel S, Jensenius JC, Trudesson L, Sjoholm AG. Mannan-binding lectin activates $\mathrm{C} 3$ and the alternative complement pathway without involvement of $\mathrm{C} 2 . J$ Clin Invest. 2006;116:1425-1434.

[ 4] Bonina L, Iannello D, Merendino R, Arena A, Mastroeni P. Tumor-dependent resistance of rat peritoneal macrophages to herpes simplex virus. Infect Immun. 1983;39:575-579.

[5] Mogensen SC. Genetics of macrophage-controlled resistance to hepatitis induced by herpes simplex virus type 2 in mice. Infect Immun. 1977;17:268-273.

[6] Scieux C. Herpes simplex virus and macrophages. Pathol Biol. 1997;45:159-164.
[7] Sit MF, Tonney DJ, Rothstein JL, Morhan PS. Effect of macrophage activation on resistance of mouse peritoneal macrophages to infection with herpes simplex virus types 1 and 2. J Gen Virol. 1988;69:1990-2100.

[8] Orzechowska B, Antoszków Z, Błach-Olszewska Z. Individual differentiation of innate antiviral immunity in humans; the role of endogenous interferons and tumor necrosis factor in the immunity of leukocytes. Arch Immunol Ther Exp. 2003; 51:51-60.

[9] Paradowska E, Błach-Olszewska Z, Sender J, Jarosz W. J. Antiviral nonspecific immunity of human placenta at term: possible role of endogenous tumor necrosis factors and interferons. Interferon Cytokine Res. 1996;16:941-948.

[10] Zaczyńska E, Błach-Olszewska Z. Effect of cyclosporine A on the non-specific, innate antiviral immunity of mice. Arch Immunol Ther Exp. 2001;49:53-57.

[11] Zaczyńska E, Błach-Olszewska Z, Gejdel E. Production of cytokines with antiviral activity by endothelial cells. $J$ Interferon Cytokines Res. 1995;15:811-814.

[12] Coil DA, Miller AD. Phosphatidylserine is not the cell surface receptor for vesicular stomatitis virus. J Virol. 2004;78: 10920-10926.

[13] Rybka K, Orzechowska B, Siemieniec I, Leszek J, Zaczyńska E, Pająk J, Błach-Olszewska Z. Age related natural antiviral non-specific immunity of human leukocytes. Med Sci Monit. 2003;9:413-417.

[14] Błach-Olszewska Z, Zaczyńska E, Kiełbiński M, Frydecka I. Deficiency of innate immunity of leukocytes is associated with the failure of the induction of remission and survival time in patients with acute leukemia. Polish J Enironmental Studies. 2005;14: 36-40.

[15] Zitvogel L. Dendritic and natural killer cells cooperate in the control-switch of innate immunity. J Exp Med. 2002;195:914.

[16] Błach-Olszewska Z. Control of over-activated innate immunity. Post Hig Med Dośw. 2006;60:201-208.

[17] Ferlazzo G, Munz C. NK cell compartments and their activation by dendritic cells. J Immunol. 2004;172:1333-1339.

[18] Meadows SK, Eriksson M, Barber A, Sentman Cl . Human NK cell IFN-gamma production is regulated by TGF-beta. Int Immunopharmacol. 2006;6:1020-1028.

[19] Rosenthal Kl, Zinkernagel RM, Hengartner H, Groscurt P, Dennert G, Takayesu D, Prevec L. Persistence of vesicular stomatitis virus in cloned interleukin-2-dependent natural killer cell lines. $J$ Virol. 1986;60:539-547.

Submitted: 28 June, 2007 Accepted after reviews: 22 December, 2007 